\title{
Editorial
}

\section{HOSPITALES: ¿HABRÁ FUTURO?}

A

ntes de hablar del hospital del futuro debemos plantearnos ¿Cuál es el futuro de nuestros hospitales? resultado de la crisis del sistema y no su causa. En el modelo de aseguramiento vigente no es claro el futuro para los hospitales públicos en Colombia, debido a que está basado en un modelo de libre mercado de la salud, manejado por empresas privadas con ánimo de lucro (Entidades Promotoras de Salud EPS); además de la competencia desleal existente entre los hospitales y las clínicas que pertenecen a las EPS, y las entidades públicas y privadas que han generado una especie de guerra del centavo ya experimentada en otros renglones de la economía, con resultados desalentadores.

A menos que se realicen correctivos de fondo, los hospitales públicos no podrán continuar con la extraordinaria función que han venido cumpliendo hasta el momento. Un ejemplo es la atención que estas instituciones prestan a sectores específicos de la población con patologías que representan una baja rentabilidad económica pero con una muy alta rentabilidad social, cuya oferta siempre ha estado presente y debe continuar siendo suministrada en el futuro. Es el caso de los servicios de pediatría que se han venido cerrando en las instituciones privadas dada su baja rentabilidad económica.

Es importante rescatar el papel de lo que es realmente público en los servicios de salud y educación, pues representan un derecho de la población y no un servicio para comerciar bajo las leyes del libre mercado. Por lo tanto, deben reevaluarse los conceptos que priman en algunos sectores del país, según los cuales la gran parte de asignaciones realizadas para generar ganancias lucrativas se denominan "inversión", mientras que las asignaciones realizadas a los hospitales públicos, para prestar servicios a la población pobre y vulnerable se denominan "gasto público". Por otra parte, con la organización sanitaria actual difícilmente se podrá lograr articular el sistema existente, el cual luce fragmentado entre sus niveles de atención, con las entidades aseguradoras y prestadoras de salud, que carecen de cualquier red de atención real, como es el caso de la red materna y perinatal a nivel nacional.

Hoy en día, según la Organización Panamericana de la Salud (OPS), la tendencia mundial en términos de un modelo de atención médica es el de la organización de redes que proporcionan asistencia sanitaria, lo cual permite la organización de un modelo de atención integral de salud, entendido como un conjunto de acciones que promueven y facilitan la atención eficiente, efectiva y oportuna, dirigido más que a la enfermedad a las personas, considerando que son sujetos de derechos en su integridad física y mental, que como seres humanos dentro de un contexto social e histórico pertenecen a diferentes tipos de familias y comunidades, en un proceso continuo de integración y adaptación a su medio ambiente físico, social y cultural. ${ }^{1}$

En este sentido, el Consejo Directivo de la OPS en la Resolución CD49.R22 de 2009, sobre Redes Integradas de Servicios de Salud (RISS) basadas en la Atención Primaria de Salud (APS), además de expresar la preocupación de los Estados miembros "por los altos niveles de fragmentación de los servicios de salud y por su repercusión negativa en el desempeño general de los sistemas de salud", manifiesta el convencimiento de "que las redes integradas de servicios de salud constituyen una de las principales expresiones operativas del enfoque de la APS a nivel de la prestación de servicios de salud. ${ }^{1}$ 
En el mismo documento, la OPS define las RISS como "una red de organizaciones que presta, o hace los arreglos para prestar, servicios de salud equitativos e integrales a una población definida, y que está dispuesta a rendir cuentas por sus resultados clínicos y económicos y por el estado de salud de la población a la que sirve".

Al leer integralmente la definición de RIIS que fue parcialmente copiada en la Ley 1438 de 2011, vemos cómo nuestros hospitales están lejos de ese planteamiento, toda vez que nuestro actual sistema los lleva a formar parte de un sistema fragmentado y segmentado de atención. Nuestros hospitales no se complementan, compiten entre sí. Además, en opinión del escritor, nuestro modelo de atención está fuertemente orientado a lo curativo y tiene como eje la actividad con relación a la cama hospitalaria y a la facturación por paciente atendido, siendo esta última en donde se concentran el gasto económico, la atención de la ciudadanía, la preocupación de los actores políticos, del gobierno nacional y territorial.

Nuestro modelo de atención en salud ha centrado sus prioridades en lo asistencial, no en el principal trabajo intersectorial que conduce a generar las acciones definitivas para afectar los factores determinantes de la salud y la calidad de vida de la población.

La lectura de la realidad colombiana deja claro que aún en las experiencias más exitosas y con mejores indicadores de salud, como el caso de en Bogotá DC, falta mucho por recorrer y que en respuesta a los cambios epidemiológicos, demográficos, tecnológicos y socio culturales, los hospitales tendrán que redefinirse y abordar profundas reformas de carácter estructural para hacer viable la implementación de redes integradas de servicios de salud; es decir, nuestra cruda realidad nos invita a pensar primero en el futuro de nuestros hospitales, en su sostenibilidad, antes que en los hospitales del futuro.

Sin duda, la Conferencia Mundial de la Salud celebrada en Alma Ata en el año de 1978, marcó un hito importante en la concepción y en el desarrollo de los sistemas de salud a nivel mundial, al definir una meta concreta: "Salud para todos en el año 2000", además, señaló una estrategia para el fortalecimiento de la respuesta organizada con el fin de reducir las inequidades en salud, promover el desarrollo de sistemas de salud que impactaran positivamente los determinantes sociales y ambientales de la enfermedad, llamada Atención Primaria en Salud (APS). ${ }^{3}$

Después de más de tres décadas, el cumplimiento de los principios establecidos en Alma Ata se han vuelto más necesarios que nunca, y han tomado renovada fuerza con el creciente reconocimiento de que los sistemas de salud basados en la APS, resultan más equitativos y conllevan a obtener mejores resultados en salud.

El informe mundial de la salud del año 2008 convocó a nuevas reformas necesarias para reorientar los sistemas sanitarios hacia el ideal de salud para todos y "para conseguir sistemas de salud centrados en las personas". En materia de servicios de salud, el informe de la OMS 2008 plantea la necesidad de reformas para alcanzar la cobertura universal, reformas para el mejoramiento de la calidad en la prestación de servicios, y reformas de las políticas públicas. ${ }^{4}$

Para enfrentar estos nuevos retos, los Estados miembros de la OPS han acordado impulsar procesos de renovación de la APS definidos como "un enfoque amplio de la organización y operación de los sistemas de salud, que haga del derecho a alcanzar el mayor nivel de salud posible su principal objetivo, al tiempo que maximiza la equidad y la solidaridad del sistema”.

\section{Herman Redondo Gómez, M.D.}

Director de Desarrollo de Servicios

Secretaría Distrital de Salud

\section{REFERENCIAS}

1. Organización Panamericana de la Salud (OPS). Exposición de motivos. Resolución CD49.R22; 2009.

2. Congreso de Colombia. Ley 1438 de 2011. Título VI. Capítulo II. Artículo 60.

3. Organización Mundial de la Salud (OMS). Conferencia Internacional Atención Primaria en Salud; 1978 septiembre 6-12; Alma Ata, Kazajstán.

4. Organización Mundial de la Salud (OMS). Informe sobre la Salud en el Mundo. La atención primaria en salud más necesaria que nunca. Ginebra, Suiza; 2008. 